\title{
Bone loss following spinal cord injury
}

This article was published in the following Dove Press journal:

Journal of Neurorestoratology

23 May 2014

Number of times this article has been viewed

\section{Ali H Otom \\ M Rami Al-Ahmar \\ Rheumatology and Rehabilitation Department, Royal Rehabilitation Centre, King Hussein Medical Centre, Amman, Jordan}

Background: The purpose of this study was to evaluate the pattern of bone loss and its consequences in a group of spinal cord injury (SCI) patients managed at the Spinal Unit-Royal Rehabilitation Centre, King Hussein Medical Centre, and its correlation with level and extent of injury, age, and time since injury.

Methods: Bone mineral density (BMD) was measured by dual energy x-ray absorptiometry at the lumbar spine and femoral neck in a group of patients who had suffered an SCI a mean of 8.6 (range 1-31) years earlier and had completed their medical and rehabilitation program during the period July 2003 to December 2013. The patients were diagnosed to have osteoporosis according to World Health Organization criteria and their fracture risk was estimated from this score using published data. The severity of their spinal injuries ranged from class A to D according to American Spinal Injury Association criteria.

Results: Of the 55 patients included in the study, 45 were male and ten were female, with a male to female ratio of 4.5:1. Their mean age was 39.5 (range 13-61) years. Bone loss indicated by low BMD revealed that the femoral region was predominantly affected, with relative preservation of the lumbar spine. Abnormal BMD values were detected in $83.6 \%$ of subjects, and fractures occurred in $16.4 \%$ following minor trauma. A positive correlation was noted between time since injury and degree of osteoporosis. Individuals with complete lesions showed lower BMD values than those with incomplete lesions. No significant correlation was found with age or sex.

Conclusion: SCI patients are at high risk of developing osteoporosis, which can lead to significant morbidity, particularly lower extremity fractures without significant trauma. Prevention and early treatment of bone loss are important in this patient group to avoid further functional impairment.

Keywords: osteoporosis, spinal cord injury, bone loss, bone mineral density, American Spinal Injury Association

\section{Introduction}

Spinal cord injury (SCI) is a multisystem injury with life-threatening complications. Bone loss as a consequence of this injury has been of secondary concern in the literature, despite its serious consequences for affected persons. Osteoporosis is a condition characterized by low bone mass and deterioration of the skeletal microarchitecture, ${ }^{1}$ and is a well known complication of SCI. ${ }^{2}$

The mechanism of bone loss in SCI is not completely understood; however, a significant amount of bone loss occurs during the first 4-6 months after injury and stabilizes between months 12 and 16. Bone demineralization reaches almost 50\% by the end of the first year following SCI. However, bone mineral loss continues
Correspondence: Ali H Otom Spinal Unit-Royal Rehabilitation Centre, King Hussein Medical Centre, PO Box 540585, Amman I 1937, Jordan Email aliotom@hotmail.com (c) (i) (8) 2014 0tom and Al-Ahmar. This work is published by Dove Medical Press Limited, and licensed under Creative Commons Attribution - Non Commercial (unported, v3.0) BY NC Le Leense. The full terms of the License are available at http://creativecommons.org/licenses/by-nc/3.0/. Non-commercial uses of the work are permitted without any further
permission from Dove Medical Press Limited, provided the work is properly attributed. Permissions beyond the scope of the License are administered by Dove Medical Press Limited. Information on permission from Dove Medical Press Limited, provided the work is properly attributed. Per
how to request permission may be found at: http://www.dovepress.com/permissions.php 


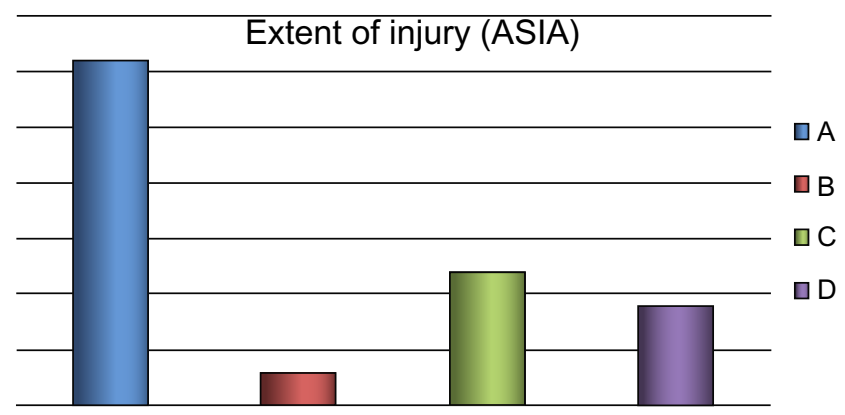

Figure I Extent of injury.

Notes: A, complete; B, sensory incomplete; C, motor incomplete (more than half of key muscle functions below the single neurological level of injury have a muscle grade less than 3); D, motor incomplete (at least half [half or more] of key muscle functions below the neurological level of injury have a muscle grade $>3$ ).

Abbreviation: ASIA, American Spinal Injury Association.

to a lesser degree in the pelvis and lower extremities over the next 10 years. ${ }^{3,4}$ The pathophysiology of SCI-induced osteoporosis is complex and differs from that observed after prolonged bed rest in patients without SCI and in those with other neurologic deficits. ${ }^{5}$ Animal studies show that there is a distinct threshold for bone loss that is related to the degree of compromise of hind limb weight-bearing, as well as a distinct threshold above which bone loss is limited according to the severity of injury. ${ }^{6} \mathrm{SCI}$ can cause immediate and, in some regions, permanent gravitational unloading, leading to disuse structural change.

SCI triggers increased activity of both osteoblasts and osteoclasts. However, osteoblastic activity increases only slightly, whereas osteoclastic activity increases significantly, peaking at 10 weeks following SCI at values 10 times the upper limit of normal. ${ }^{7}$ Hypercalciuria is $2-4$ times that of persons without SCI who undergo bed rest and reaches a peak 1-6 months post injury; this marked increase in urinary calcium is the direct result of an imbalance between bone formation and resorption. ${ }^{8}$ Acutely, the parathyroid gland

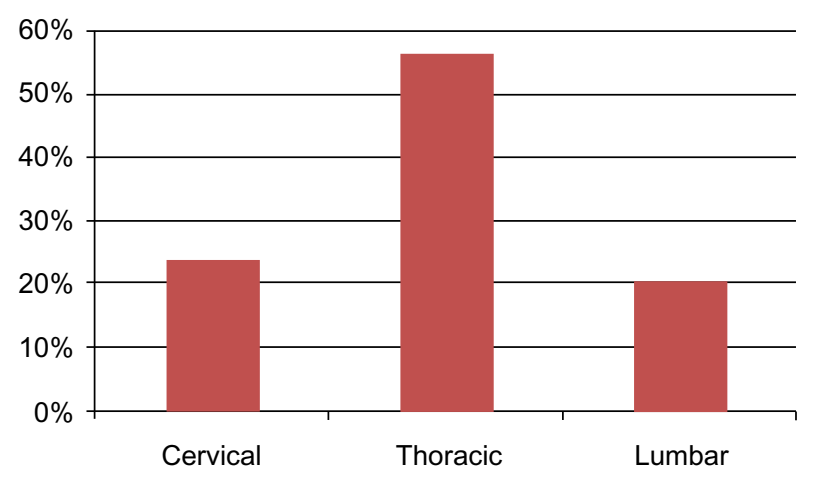

Figure 2 Level of spinal cord injury. is relatively inactive, with low parathyroid hormone levels observed in the first year following SCI. ${ }^{9}$

Complications arising from fractures and their treatment can lead to long-term hospitalization, increased costs, and further disability. The aim of the present study was to evaluate the extent of bone loss in SCI patients treated at our spinal unit and to correlate this to the level, severity of injury, age, and time since injury.

\section{Materials and methods}

The subjects were recruited from inpatients and outpatients managed in the Spinal Unit-Royal Rehabilitation Centre at King Hussein Medical Centre during the period July 2003 to December 2013. The current study is an extension of a previous brief one that included only 30 patients and was reported by the same authors. ${ }^{10}$ We decided to extend the study period in order to recruit more patients for a longer follow-up period, and to achieve more meaningful results.

All participants were medically stable upon entry into the study and gave their informed consent. We included patients with SCI at various levels (C4-L3) for more than one year and with class A, B, C, or D injuries as defined by the American Spinal Injury Association Impairment Scale ${ }^{11}$ (Figures 1 and 2). Bone mineral density (BMD) was measured in all patients by dual energy $\mathrm{X}$-ray absorptiometry at the lumbar spine and femoral region using a Hologic-Delphi ${ }^{\text {TM }}$ QDR series machine (Hologic Inc., Bedford, MA, USA).

Patients were classified according to World Health Organization criteria into three BMD groups, ie, normal, osteopenic, and osteoporotic. These groups were compared using simple descriptive statistics (ie, mean, percentage, standard deviation). Calculation of fracture risk was based on data published in international studies. ${ }^{4}{ }^{12}$ Fifty-five patients met our inclusion criteria (Table 1). All patients underwent an initial clinical evaluation by direct patient and chart review.

\section{Results}

The study group included 45 males and 10 females, with a male to female ratio of 4.5:1 (Figure 3). Their mean age was 39.5 (range 13-61) years, and the mean time since injury was 8.6 (range 1-31) years. Forty-six patients $(83.6 \%)$ were found to have abnormal BMD. According to World Health Organization criteria for osteoporosis, 22 subjects (40\%) were osteoporotic, 24 (43.6\%) were osteopenic, and nine (16.4\%) had normal BMD. Individuals with complete lesions had lower BMD than those with incomplete lesions, suggesting an inverse correlation between BMD and severity of SCI (Table 2). Bone 
Table I Causes of spinal cord injury in patients followed at King Hussein Medical Centre from July 2003 to December 2013

\begin{tabular}{ll}
\hline Traumatic & Nontraumatic \\
\hline $\mathrm{n}=40$ & $\mathrm{n}=15$ \\
$72.7 \%$ & $27.3 \%$ \\
\hline
\end{tabular}

loss indicated by low BMD showed a regional pattern, affecting the femoral region more than the lumbar spine. No significant correlation was found with regard to sex in this study. A positive correlation was noted between time since injury and degree of osteoporosis (Table 3 ). Fractures post SCI occurred in nine patients $(16.4 \%)$, the majority of these $(80 \%)$ involving the lower limbs without significant trauma.

\section{Discussion}

SCI leads to devastating neurologic impairment, and also triggers rapid and sustained bone loss. Further, progress in the management of SCI has prolonged patient survival, so the incidence of secondary bone and joint disorders has also increased. ${ }^{13}$ The advent of bone densitometry has enabled measurement of bone mass and quantification of fracture risk before a fracture occurs. Szollar et al reported that bone loss was detectable by densitometry in all age groups by 12 months post SCI. ${ }^{14-16}$

Osteoporosis following SCI needs careful consideration in affected individuals, and special attention is necessary early in the course of their management. Ideally, intervention should be provided early as a large portion of bone loss occurs within the first 6 months after SCI, stabilizing at values of $60 \%-70 \%$ of normal in the femoral neck and $40 \%-50 \%$ in the proximal tibia by $12-24$ months. ${ }^{15,16}$

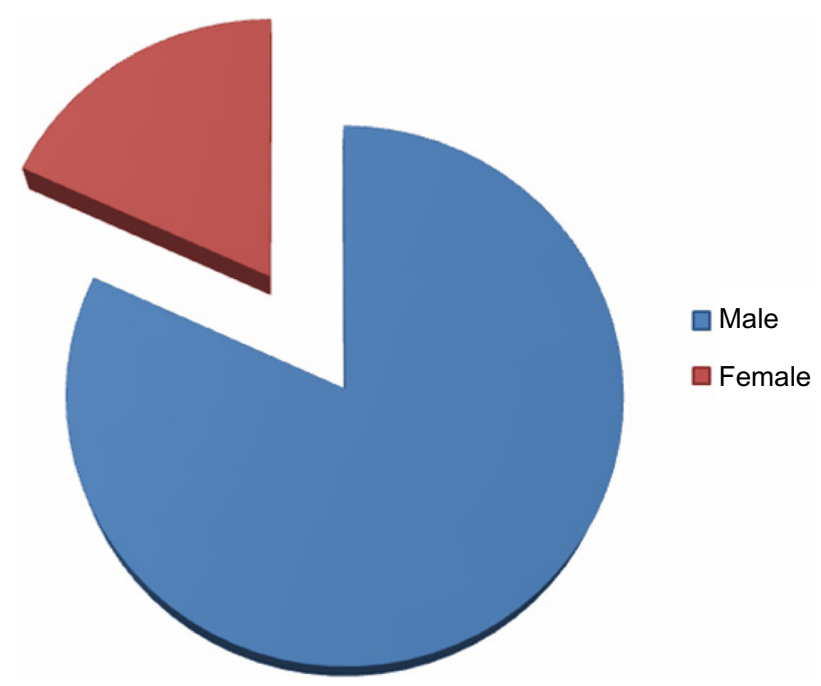

Figure 3 Male to female ratio of patients with spinal cord injury (4.5:I).
Table 2 BMD in patients with spinal cord injury followed at King Hussein Medical Centre from July 2003 to December 2013

\begin{tabular}{llllll}
\hline $\begin{array}{l}\text { BMD } \\
\text { classification }\end{array}$ & $\begin{array}{l}\text { Patients } \\
\text { (n) }\end{array}$ & $\%$ & $\begin{array}{l}\text { T score } \\
\text { (mean } \pm \\
\text { SD) }\end{array}$ & $\begin{array}{l}\text { Z score } \\
\text { (mean } \pm \\
\text { SD) }\end{array}$ & $\begin{array}{l}\text { Mean } \\
\text { BMD, } \\
\text { g/cm }\end{array}$ \\
\hline Osteoporotic & 22 & 40 & $-3.08 \pm 0.354$ & $-2.93 \pm 0.428$ & 0.564 \\
Osteopenic & 24 & 43.6 & $-1.53 \pm 0.358$ & $-2.84 \pm 0.399$ & 0.784 \\
Normal & 9 & 16.4 & $-0.10 \pm 0.696$ & $0.41 \pm 0.858$ & 0.936 \\
Complete & 31 & 56.4 & -2.68 & & 0.618 \\
Incomplete & 24 & 43.6 & -1.85 & & 0.756 \\
\hline
\end{tabular}

Abbreviations: BMD, bone mineral density; SD, standard deviation.

It is known that fractures of the lower extremities following minor trauma are more prevalent in SCI patients than in the general population, ie, $2 \%$ versus $1 \%$ per year, respectively. ${ }^{17}$ Fractures frequently occur during falls from a wheelchair, with minimal force during transfers, or while exercising. When fractures occur in individuals with SCI, they often go unnoticed and are diagnosed late. ${ }^{18}$ Our study documented loss of bone mass in $83.6 \%$ of individuals with SCI, with osteoporosis found in $40 \%$ of cases. Patients with osteoporosis had predominantly complete lesions and the time since injury was longer. ${ }^{3}$ This is consistent with previous findings that hip BMD declines with increasing age and time since SCI. ${ }^{19-21}$ No significant correlation was found with regard to sex, probably because the majority of the patients were male and relatively young (median age 39.5 years).

The frequency of fracture in this group of SCI patients was $16.4 \%$, which is higher than the $1 \%-6 \%$ fracture rate reported in the literature, with a study by Lazo et al reporting an even higher (34\%) incidence of fracture. ${ }^{20}$

In the first year after SCI, $15 \%-35 \%$ of BMD is lost from the three sites at greatest risk for fracture, ie, the distal femur, proximal tibia, and distal tibia. ${ }^{18}$ In our study, the regional pattern of bone loss as indicated by low BMD indicated that the femoral region was the worst affected, while the lumbar spine was better preserved; this is in agreement with other studies and could be due to the weight-bearing role of and impact through the lumbar spine during wheelchair activities and regular standing exercises. ${ }^{21-23}$

Table 3 Distribution of BMD according to duration of $\mathrm{SCl}$

\begin{tabular}{lll}
\hline Years since SCI & Patients (n) & Mean BMD, $\mathbf{g} / \mathbf{c m}^{2}$ \\
\hline$<5$ & 15 & 0.775 \\
$5-10$ & 22 & 0.650 \\
$\geq 11$ & 18 & 0.594 \\
\hline
\end{tabular}




\section{Conclusion}

SCI patients are at high risk of osteoporosis that can be complicated by fracture, cause significant morbidity, and disable the patient further, so prevention and treatment of osteoporosis is an important measure to avoid additional functional impairment. BMD measurements can be used for diagnosis and assessment of fracture risk in SCI patients.

\section{Disclosure}

The authors report no conflicts of interest in this work.

\section{References}

1. Goddard D, Kleerekoper M. The epidemiology of osteoporosis. Postgrad Med. 1998;104:54-72.

2. Gerland DE, Stewart CA, Adkins RH, et al. Osteoporosis after spinal cord injury. J Orthop Res. 1992;10:371-378.

3. Demirel G, Yilmaz H, Paker N, Onel S. Osteoporosis after spinal cord injury. Spinal Cord. 1998;36:822-825.

4. Jiang S-D, Dai L-Y, Jiang L-S. Osteoporosis after spinal cord injury. Osteoporos Int. 2006;17:180-192.

5. Yilmaz B, Yasar E, Goktepe AS, et al. The relationship between basal metabolic rate and femur bone mineral density in men with traumatic spinal cord injury. Arch Phys Med Rehabil. 2007;88:758-761.

6. Voor MJ, Brown EH, Xu Q, et al. Bone loss following spinal cord injury in a rat model. J Neurotrauma. 2012;29:1676-1682.

7. Weiss D, Yada R, Talaver F, Foye P. Osteoporosis and spinal cord injury. Available from: http://emedicine.medscape.com/article/322204overview. Accessed April 21, 2014.

8. Kaplan PE, Roden W, Gilbert E, Richards L, Goldschmidt J. Reduction of hypercalciuria in tetraplegia after weight-bearing and strengthening exercises. Paraplegia. 1981;19:289-293.

9. Claus-Walker J, Carter RE, Compos RJ, Spencer WA. Hypercalcemia in early traumatic quadriplegia. J Chronic Dis. 1975;28:81-90.

10. Otom A, Al-Ahmar MR. Osteoporosis following spinal cord injury. Journal of the Royal Medical Services. 2012;19:68-71.
11. American Spinal Injury Association. International Standards for Neurological Classification of Spinal Cord Injury. Revised 2002. Chicago, IL, USA: American Spinal Injury Association; 2006.

12. World Health Organization, National Osteoporosis Foundation. Clinician's Guide to Prevention and Treatment of Osteoporosis. Geneva, Switzerland: World Health Organization; 2010.

13. Pedrera JD, Manas P, Gomez MA, et al. Ultrasound bone mass in paraplegic patients. Spinal Cord. 2002;40:83-87.

14. Ryan PJ. Overview of role of BMD measurements in managing osteoporosis. Semin Nucl Med. 1997;27:197-207.

15. Wilmet E, Ismail AA, Heilporn A, Welraeds D, Bergmann P. Longitudinal study of the bone mineral content and soft tissue composition after spinal cord section. Paraplegia. 1995;33:674-677.

16. Szollar SM, Martin EM, Sartoris DJ, Parthemore JG, Deftos LJ. Bone mineral density and indexes of bone metabolism in spinal cord injury. Am J Phys Med Rehabil. 1998;77:28-35.

17. Vestergaard P, Krogh K, Rejnmark L, Mosekilde L. Fracture rates and risk factors for fractures in patient with spinal injury. Spinal Cord. 1998;36:790-796

18. Dudley-Javoroski S, Shields RK. Regional cortical and trabecular bone loss after spinal cord injury. J Rehabil Res Dev. 2012;49: 1365-1376.

19. Ragnarsson KT, Sell GH. Lower extremity fractures after spinal cord injury. Arch Phys Med Rehabil. 1981;62:418-423.

20. Lazo MG, Shirazi P, Sam M, Giobbie-Hurder A, Blacconiere MJ, Muppidi M. Osteoprosis and risk of fracture in men with spinal cord injury. Spinal Cord. 2001;39:208-214.

21. Biering-Sorensen $\mathrm{F}$, Bohr H, Schaadt O. Bone mineral content of the lumbar spine and lower extremities years after spinal cord lesion. Paraplegia. 1988;26:293-301.

22. Geomaere S, Van Learem, De Neve P, Kaufman JM. Bone mineral status in paraplegic patients who do or do not perform standing. Osteoporos Int. 1994;4:138-143.

23. Fattal C, Mariano-Goulart D, Thomas E, Rouays-Mabit H, Verollet C, Maimoun L. Osteoporosis in persons with spinal cord injury: the need for a targeted therapeutic education. Arch Phys Med Rehabil. 2011;92: 59-67.
Journal of Neurorestoratology

\section{Publish your work in this journal}

The Journal of Neurorestoratology is an international, peer-reviewed, open access online journal publishing original research and review articles on the subject of Neurorestoratology. To provide complete coverage of this revolutionary field the Journal of Neurorestoratology will report on relevant experimental research, technological advances, and

\section{Dovepress}

clinical achievements. The manuscript management system is completely online and includes a very quick and fair peer-review system, which is all easy to use. Visit http://www.dovepress.com/testimonials.php to read real quotes from published authors. 